\title{
ESTUDOS TAXIONÔMICOS E BIOLOGICOS SÔBRE BUPRESTIDEOS MINADORES DO GENERO PACHYSCHELUS SOLIER, 1833, COM A DESCRIÇÃO DE UMA ESPÉCIE NOVA (Insecta, Coleoptera) *
}

\author{
MARCOS KOGAN \\ Instituto Oswaldo Cruz, Rio de Janeiro, Guanabara \\ (Com 47 figuras no texto)
}

Apresentamos as conclusões de estudos taxionômicos e biológicos sôbre duas espécies do gênero Pachyschelus Solier, 1833. Uma delas é descrita como nova. Da outra, P. mimus Obenberger, 1925, descrevemos o alótipo macho. Incluímos observações sôbre as formas pós-embrionárias, os hospedeiros e as minas de ambas as espécies.

O material estudado resulta principalmente de coletas realizadas em dias do mês de março de 1963, nos Estados do Rio de Janeiro e Guanabara.

A situação atual dos conhecimentos sôbre a biologia dos buprestídeos minadores foi discutida em trabalho recente (KogAN, 1963).

Agradecemos à Dra. Maria C. Monteiro, da Seção de Agrostologia do I.P.E.A.C.S., a gentileza da determinação das espécies de plantas hospedeiras.

Pachyschelus urvilleae sp. n.

(Figs. 1-26)

Macho - Conformação geral ovalada, em arco aberto e quase contínuo, desde a cabeça até o limite do $1 / 4$ basal dos élitros, onde atingem a maior largura, daí para o ápice os élitros convergem em linha levemente arqueada sendo o ângulo sutural arredondado. Tegumento dorsal glabro, nitidamente pontuado no pronoto e com pontuação sub-seriada nos élitros. Coloração geral (sob luz incandescente, incidente) - cabeças e pronoto negros-esverdeados, élitros e escutelo negros com

* Recebido para publicação a 4 de junho de 1963.

Trabalho do Instituto Oswaldo Cruz (Divisão de Zoologia) , Realizado, parcialmente, com auxílio do Conselho Nacional de Pesquisas. 
reflexos violáceos. Comprimento $2,48 \mathrm{~mm}$; maior largura (entre o $1 / 4$ basal e o $1 / 4$ médio basal dos élitros) : $1,70 \mathrm{~mm}$.
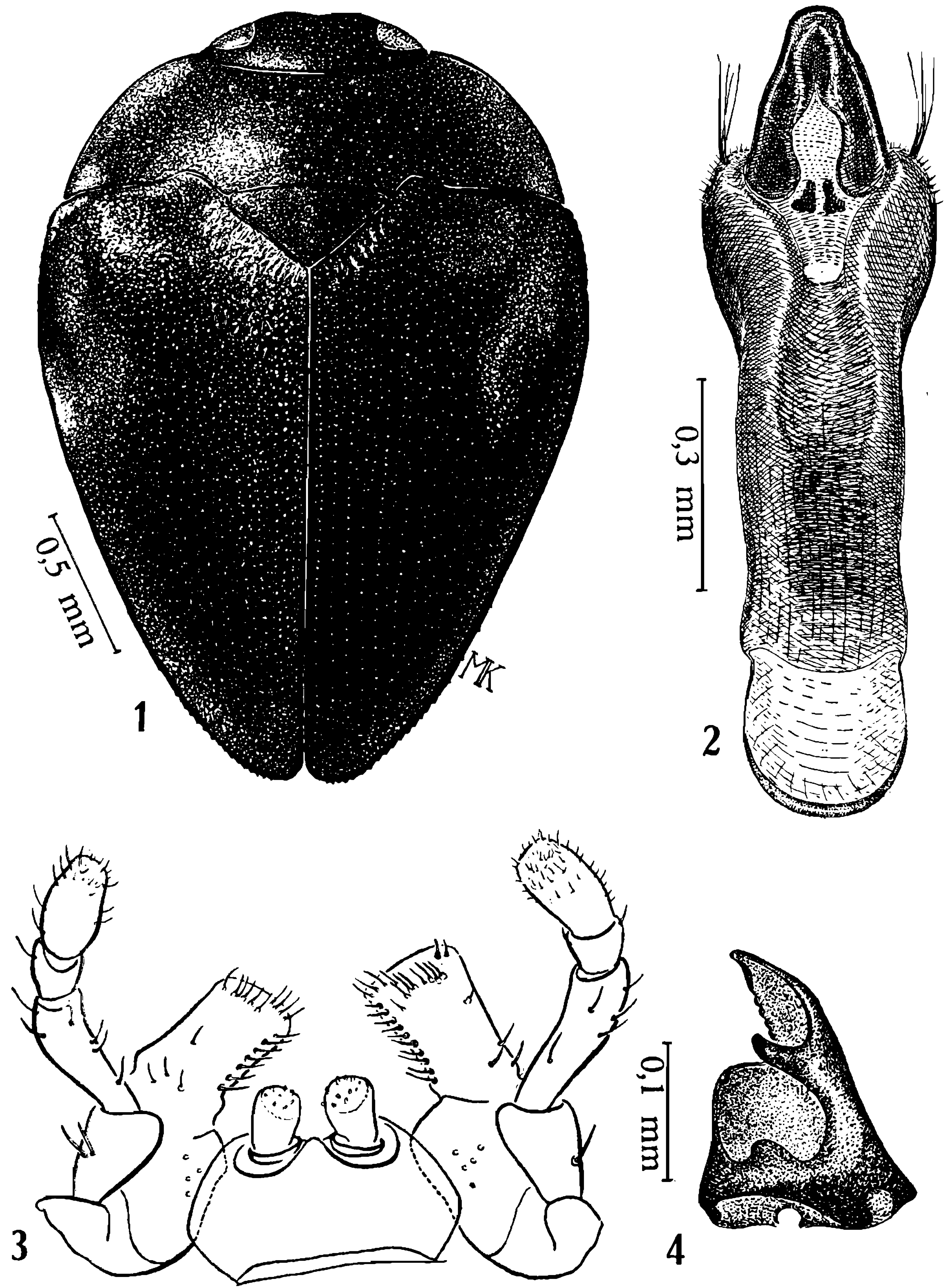

Pachyschelus urvilleae sp. n. - Holótipo macho - Fig. 1: Vista dorsal; fig. 2: edeago, vista dorsal; parátipo macho - fig. 3: maxilas, palpos maxilares e lábio inferior, vista ventral; fig. 4: mandíbula. 
Cabeça: Vértex e fronte muito largos, fronte levemente sulcada. Glabra. Epístoma na porção supra-antenal formado por duas peças triangulares separadas da fronte por duas depressões alongadas; a separação entre as cavidades antenais se restringe a uma fina crista que se expande em uma peça em arco na porção sub-antenal. Labro subretangular, fortemente esclerozado. Mandíbulas, (fig. 4) com a ponta afilada, corpo profundamente escavado, uma crista levemente crenulada e outra com um longo dente recurvado, voltado para o ápice e para dentro. Maxila (fig. 9) com o lobo apical sub-quadrangular, com

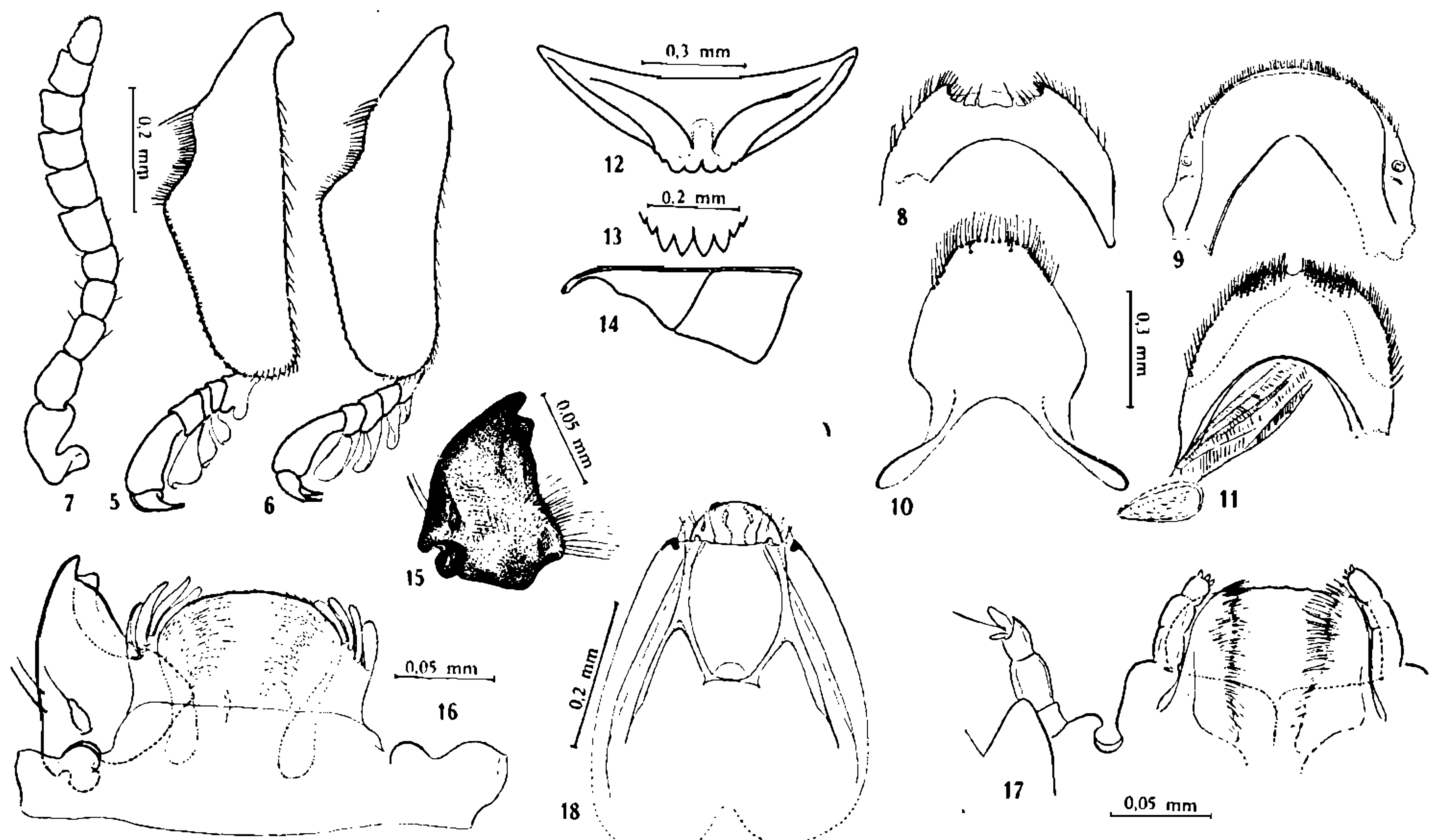

Pachyschelus urvilleae sp. n. - Holótipo macho - Flg. 5: Tibia + tarso posterior esquerdo, vista ventral; alótipo fêmea - fig. 6: tíbia + tarso posterior esquerdo, vista ventral; holótipo macho - fig. 7: antena; fig. 8: VIII-esternito; fig. 9: VIII-tergito; fig. 10: IX-esternito; fig. 11: IX+X-tergito; alótipo fêmea - fig. 12: VII-esternito, vista ventral; fig. 13: bordo anal do VII-esternito visto de cima; fig. 14: VII-esternito, vista lateral; larva - fig. 15: mandíbula esquerda, vista dorsal; flg. 16: labro e mandibula esquerda, vista dorsal; fig. 17: lábio, maxilas e antenas, vista dorsal; fig. 18: cápsula cefálica, vista, dorsal.

pêlos sensoriais nas margens, palpos tri-segmentados, segmento I troncônico, alongado e recurvado, II - muito curto, III — sub-cilíndrico, 3 vêzes mais longo que II e com $2 / 3$ do comprimento de I. Lábio inferior hexagonal, irregular; palpos labiais bi-segmentados, segmento I muito curto e largo; II cilíndrico, com papilas apicais pequenas. Antenas com segmento I recurvado e espessado na extremidade, II mais largo e de comprimento semelhante a III; IV e V sub-iguais, VI - X sub-quadrangulares, XI - arredondado na ponta. Olhos não salientes, muito afastados no vértex, sem atingir a margem do pronoto, aproximados em baixo junto às cavidades antenais. Largura na base: $0,70 \mathrm{~mm}$; largura entre os olhos: $0,34 \mathrm{~mm}$.

Tórax: Pronoto - comprimento na linha mediana: $0,36 \mathrm{~mm}$; largura entre os ângulos umerais: $1,58 \mathrm{~mm}$; tegumento muito finamente 
chagrinado, mais nìtidamente nas margens, com pontos grossos e rasos, esparsos por tôda a superfície, inclusive no disco; coloração negra levemente esverdeada sob luz de lâmpada incandescente, em incidência direta; glabro; bordo anterior levemente escavado em arco muito aberto; bordo posterior com uma projeção estreita para adiante de cada lado da zona escutelar, diante do escutelo em arco muito aberto; margens laterais levemente relevadas, em arco acentuado no $1 / 3$ anterior e atenuado nos $2 / 3$ posteriores. Escutelo grande em triângulo isósceles, com os ângulos basais truncados; largura na base: $0,26 \mathrm{~mm}$; comprimento na linha mediana: $0,24 \mathrm{~mm}$. Proesterno levemente abaulado, negro, liso, com pêlos testáceos, de comprimento médio, reclinado para trás e para dentro; sulcos pro-esternais recurvados e oblíquos, pouco acentuados. Peças laterais do mesoesterno recurvadas em crescente, muito afastadas. Cavidade esternal muito pouco acentuada. Metaesterno sub-plano, com pêlos testáceos reclinados para trás, mais curtos que os do proesterno.

Elitros: Ligeiramente mais largos entre o $1 / 4$ basal e o $1 / 4$ médio basal; as margens laterais do $1 / 4$ basal irregulares, divergentes para trás, e levemente arqueadas, $3 / 4$ posteriores convergentes para o ângulo sutural em arco muito atenuado, $1 / 4$ apical com um serrilhado muito fino e pouco conspícuo, ângulo sutural arredondado. Calo umeral nítido, um tanto fino; depressões pós-umerais acentuadas; depressões periescutelares muito atenuadas. Tegumento glabro, negro com reflexos violáceos, finamente corrugado nos limites com o escutelo, uniformemente pontuado, com pontuações finas.

Abdômen: Negro, levemente chagrinado; com pêlos testáceos muito curtos em alinhamento transversal irregular nos segmentos basais e com um tufo de pêlos longos no ápice do pigídio. Pigídio acuminado. Genitália (figs. 2, 8-11) com o edeago curto e largo, parâmeros alargados no $1 / 3$ apical e com um tufo de pêlos longos; ponta do pênis alongada sub-triangular com a extremidade truncada; placa basal curta arredondada, hialina. Esternito VIII largamente escavado no bordo externo, com pêlos grossos emergindo, no meio, de processos pedunculados; esternito IX alargado e com o bordo externo guarnecido por uma série de pêlos emergindo de pontos nítidos; tergito VIII com a margem apresentando uma fileira de pêlos curtos e uniformes; tergito IX $+\mathbf{X}$ com uma pequena reentrância em arco, no meio do bordo externo e com pêlos médios e grossos.

Patas: Tíbias do $3 .^{\circ}$ par (fig. 5) com a margem externa apresentando um crenulado fino e interrompido, na metade distal. Com uma reentrância afetando o 1/4 médio-basal guarnecida por cêrca de 28 cerdas negras e mais 2 ou 3 proximais, mais claras. Margem interna ligeiramente sinuosa e com pêlos reclinados. Tarsos curtos, lamelas desenvolvidas

Holótipo - Macho n. ${ }^{\circ} 12.101$ na coleção de Coleoptera do Instituto Oswaldo Cruz; Barra da Tijuca, Rio de Janeiro, GB, Brasil, 8 de março de 1963, M. Kogan; 4 parátipos - mesmos dados do holótipo - depositados nas seguintes coleções: Campos Seabra (1), M. Kogan (3) . 
Fêmea (principais proporções) - Comprimento: $2,48 \mathrm{~mm}$; largura (entre o $1 / 4$ basal e o $1 / 4$ médio-basal dos élitros) : $1,68 \mathrm{~mm}$; comprimento do pronoto: $0,36 \mathrm{~mm}$; largura do pronoto: $1,56 \mathrm{~mm}$; comprimento do escutelo: $0,24 \mathrm{~mm}$; largura do escutelo: $0,26 \mathrm{~mm}$; largura da cabeça: $0,72 \mathrm{~mm}$; largura entre os olhos: $0,32 \mathrm{~mm}$.
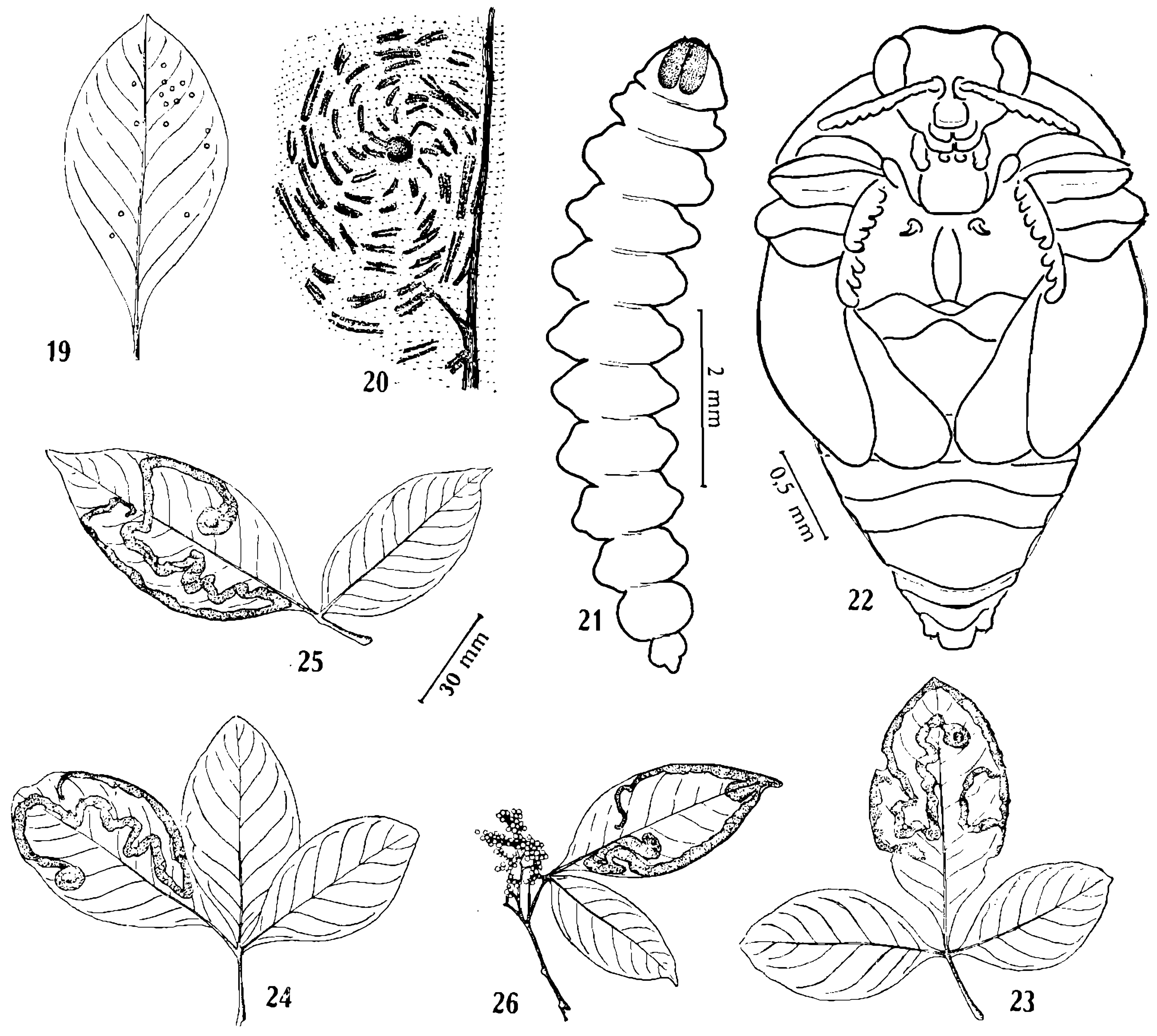

Pachyschelus urvilleae sp. n. - Fig. 19: Fôlha com a indicação esquemática da localização de 16 posturas; fig. 20: ôvo cercado de escaras em hélice, na face ventral da fôlha de Urvillea glabra; fig. 21: prépupa, fase inicial; fig. 22: pupa, vista ventral; figs. 23-26; fôlhas de Urvillea glabra minadas por $P$. urvilleae sp. $\mathrm{n}$.

Conformação geral, côr e aspecto do tegumento semelhante aos do macho. Pilosidade da face ventral muito curta, mais esparsa e branca.

Bordo posterior do pigídio (figs. 12-14) com 8 dentes: 4 centrais em linha reta, alargados na base e afilados no ápice, e dois de cada lado dos centrais, os mais externos menores e mais afastados da linha formada pelos 4 centrais. Não há incisão mediana entre os dentes; externito VII com uma forte depressão alongada e com finos pêlos, muito curtos, de ambos os lados. 
Alótipo - Fêmea n. ${ }^{\circ}$ 12,102 na coleção de Coleoptera do Instituto Oswaldo Cruz; mesma procedência, data e colecionador do holótipo. 2 parátipos, mesmos dados, na coleção do autor.

Discussão $-P$. urvilleae sp. $\mathrm{n}$. aproxima-se provàvelmente de $P$. vanrooni Obenberger, 1923 pela conformação geral e estrutura do pigídio da fêmea. Em $P$. urvilleae, no entanto, não há dicroísmo sexual como o apresentado pela espécie de OBENBERGER e o denteado do pigídio da fêmea apresenta-se com 4 dentes iguais em linha reta e 2 pares laterais de dentes menores e recuados e não em um arco mais ou menos uniforme formado pelos 8 dentes sub-iguais. O tipo de genitália do macho distingue $P$. urvilleae sp. n. das espécies de Pachyschelus descritas por A. CoBos e cuja genitália é conhecida (СовоS, 1956; 1958; 1959a; $1959 b)$.

\section{DADOS BIOLÓGICOS}

Óvo e oviposição (figs. 19-20) - A oviposição se faz na página inferior da fôlha; ôvo arredondado com cêrca de $0,35 \mathrm{~mm}$ de diâmetro; córion testáceo, delgado; incluso superficialmente no tecido epidérmico, recoberto uniformemente pela película externa da epiderme da fôlha. As posturas são normalmente isoladas (1 por fôlha), algo ou muito afastadas da periferia (fig. 20).

Ao redor do ôvo observa-se uma área relativamente extensa coberta por escaras dispostas em raios curvos ou em espirais múltiplas (figura 19). Esta figura foi observada em uma fôlha, ao lado de uma postura normal, no entanto, a 2. ${ }^{a}$ lesão não apresentava ôvo no seu centro. Este fato leva-nos a supor que a fêmea produz primeiro as escaras e depois realiza a oviposição.

Larva (figs. 15-18) - Cápsulas cefálicas, obtidas de exúvias retiradas do interior das minas, apresentam as seguintes características principais: conformação geral ovalada, com uma reentrância na parte posterior. Labro largo e curto, arredondado adiante e com 4-5 pêlos espatulados de cada lado. Mandíbulas (fig. 15) com o ápice curto e recurvado, crista dorsal saliente, ventral com um dente apical; observam-se ainda, duas cerdas laterais, um tufo de pêlos basais, internos e uma cerda dorsal emergindo de um processo biglobuloso. Nesta espécie verificamos que a articulação mandibular se faz na face dorsal, por meio de uma cavidade articular profunda que aloja o côndilo frontal e, na face ventral através de um côndilo proeminente, recebido por um acetábulo da sutura gular, a musculatura abdutora e adutora ocupa a maior parte do volume da cápsula cefálica. Maxilas com o lobo apical fortemente pubescente, palpos aparentemente tri-segmentados, segmentos I-II sub-iguais, cilíndricos; III - subcilíndrico com várias papilas na ponta. Lábio largo e curto, com os ângulos laterais arredondados; palpos labiais não observados. Antenas tri-segmentadas, segmento I mais longo, abaulado no meio; II - mais curto, com uma papila lateral, curta e fina; III - digitiforme e com um longo pêlo sub-basal. 
Tentório pouco conspícuo (nos exemplares examinados), ramo dorsal em duplo "YY" invertido com os braços dorsais longos, a ponte interna com uma lamela mediana recurvada para baixo e uma ponta espiniforme de cada lado, voltada para trás, pouco conspícua, ramo ventral em dois braços longos, finos e recurvados. Olhos ou manchas ocelares não observados.

Pré-pupa (fig. 21) - Longa e estreita, verde-amarelada, clara.

Placas pronotais testáceas, sub-ovaladas, interrompidas no meio. Somitos lobados dos lados. Comprimento aproximadamente - 7,6 mm.

Pupa (fig. 22) - De coloração semelhante à da pré-pupa. Com dois espinhos recurvados no metaesterno. Encontra-se na câmara pupal com a face ventral voltada para cima.

Hospedeiro - Urvillea glabra Camb., Sapindaceae; Maria C. Monteiro det. IV-1963.

Mina (figs. 23-26) - Ofionômio, de superfície superior, típico de Buprestidae. Ao nascer a larvinha, esta procura um dos bordos da fôlha e percorre uma grande extenção do mesmo. Se o sentido da escavação é da base para o ápice a larva cruza a nervura principal no ápice e prossegue a minar o bordo oposto. Se o sentido da escavação é do ápice para a base, ao atingir a nervura principal, a larva não a cruza; começa a minar em meandros do mesmo lado do bordo inicialmente lesado.

A câmara pupal é irregular, alargada e arredondada, o opérculo é perfeitamente circular, central ou levemente excêntrico.

A coloração da mina é uniformemente castanha, clara ou escura. Destaca-se com nitidez do fundo verde da fôlha. A mina não parece provocar reações pigmentares especiais por parte da fôlha atacada.

As dejeções são filiformes, esparsas em alguns pontos e mais concentradas em outros, sem distribuição definida.

\section{QUADRO I}

Dimensões de 4 minas em fôlhas de U. glabra (em milímetros)

\begin{tabular}{|c|c|c|c|c|c|c|c|c|}
\hline MINA & $\left|\begin{array}{c}\text { da postura } \\
\text { a } 1 .{ }^{\mathrm{a}} \text { exúvia }\end{array}\right|$ & $\begin{array}{c}\text { da } 1 .^{a} \grave{a} \\
2 .^{a} \text { exúvia }\end{array}$ & $\begin{array}{c}\text { da } 2 a^{a} \\
\text { exúvia a } \\
\text { cam. pupal }\end{array} \mid$ & $\begin{array}{c}\text { Comp. } \\
\text { total }\end{array}$ & $\begin{array}{l}\text { Larg. } \\
\text { inicial }\end{array}$ & $\begin{array}{l}\text { Larg. } \\
\text { final }\end{array}$ & $\mid \begin{array}{c}\text { Diam. } \\
\text { cam. pupal }\end{array}$ & $\begin{array}{l}\text { Diam. } \\
\text { opérculo }\end{array}$ \\
\hline A. . & 15 & 27 & 141 & 183 & 1 & 3 & 8 & 2 \\
\hline $\mathbf{B} \ldots \ldots \ldots \ldots$ & 9 & 18 & 152 & 179 & 1 & 4 & 8 & 2 \\
\hline $\mathrm{C} \ldots \ldots \ldots \ldots$ & 9 & 16 & 132 & 157 & 1 & 3,5 & 8 & -- \\
\hline$\Pi \ldots \ldots \ldots \ldots$ & 10 & 24 & 175 & 209 & 1 & 4 & 8 & - \\
\hline
\end{tabular}

Inimigos naturais - Algumas larvas estavam parasitadas por Tetrastichus sp. (Aphelinidae).

Pachyschelus mimus Obenberger, 1925

(Figs . 27-47)

Pachyschelus mimus Obenberger, 1925: 62, 69, 116, fig. 55.

Pachyschelus mimus Obenberger, 1937: 1329.

Pachyschelus mimus Blackwelder, 1944: 336. 
Macho - Conformação geral em oval irregular, largamente arredondada adiante, estreitamente atrás, na união dos élitros. Tegumento dorsal muito fina e irregularmente pontuado com uma pubescência branca, curta, arqueada e reclinada, formando uma ornamentação elitral característica. Coloração geral negra brilhante. Comprimento: $2,87 \mathrm{~mm}$ (maior exemplar da série $3,10 \mathrm{~mm}$; menor exemplar: $2,76 \mathrm{~mm}$ ); maior largura (entre o $1 / 3$ médio e o basal dos élitros) : 1,75 mm $(1,93$ $-1,66)$.

Cabeça: Vértex e fronte largos, fronte nìtidamente sulcada. Apresenta uma pubescência branca, reclinada para adiante, um tanto adensada em ambos os lados do sulco frontal. Epístoma profundamente separado da fronte por duas depressões alongadas que confluem no meio, prolongando-se para baixo em um sulco entre as antenas. Labro trapezoidal. Mandíbula (fig. 28) com a ponta longa e afilada, o corpo profundamente escavado apresentando uma crista crenulada e outra ondulada com um largo dente basal. Antenas com o segmento II tão longo como III + IV e tão largo como a extremidade distal do I; VI ao IX sub-iguais, sub-quadrangulares, XI mais estreito que os anteriores e arredondado na ponta. Olhos não salientes (por vêzes até reentrantes) . Largura na base: $0,87 \mathrm{~mm}(0,94-0,80)$; largura entre os olhos: $0,35 \mathrm{~mm}(0,41-0,37)$.

Tórax: Pronoto - comprimento na linha mediana: $0,41 \mathrm{~mm}$ $(0,48-0,39)$; largura entre os ângulos umerais: $1,73 \mathrm{~mm}(1,91-1,62)$; disco brilhante, glabro, convexo; pubescência fina e branca, reclinada para fora, adensada para os lados; bordo anterior escavado em arco aberto; bordo posterior bissinuado de cada lado do escutelo e diante dêste em arco muito aberto; margens laterais lisas, em arco, ligeiramente relevadas. Escutelo grande, em triângulo isósceles com os ângulos basais truncados; largura na base: $0,55 \mathrm{~mm}(0,62-0,53)$; comprimento na linha mediana: $0,28 \mathrm{~mm}(0,30-0,25)$. Proesterno largo, quase plano, sulcos proesternais oblíquos em relação ao eixo longitudinal do corpo. Peças laterais do mesoesterno muito separadas, estreitas e em forma de vírgula. Cavidade esternal quase reta.

Elitros: Ligeiramente mais largos que o pronoto no $1 / 3$ anterior onde as margens são levemente divergentes até o $1 / 3$ médio; do $1 / 3$ médio até a base confluem quase em linha reta, formando um ângulo sutural arredondado; $1 / 3$ basal uniformemente serrilhado. Calo umeral pouco saliente. Depressões pós-umerais acentuadas; depressões peri-escutelares pouco profundas. Pontuação discal sub-seriada, muito rasa e inconspícua. Pubescência concentrada em algumas áreas formando uma ornamentação assim distribuída: 1) uma faixa em arco no bordo das depressões peri-escutelares e na região umeral; 2) uma faixa mediana em zig-zag muito acentuado, com uma expansão na direção da base próximo à sutura; 3 ) uma faixa em zig-zag mais estreita que a anterior no meio do $1 / 3$ apical e 4) uma faixa pré-apical regular, mais ou menos oblíqua. Espaços entre as faixas pilosas com uma finíssima pubescência emergindo das linhas de pontos. 

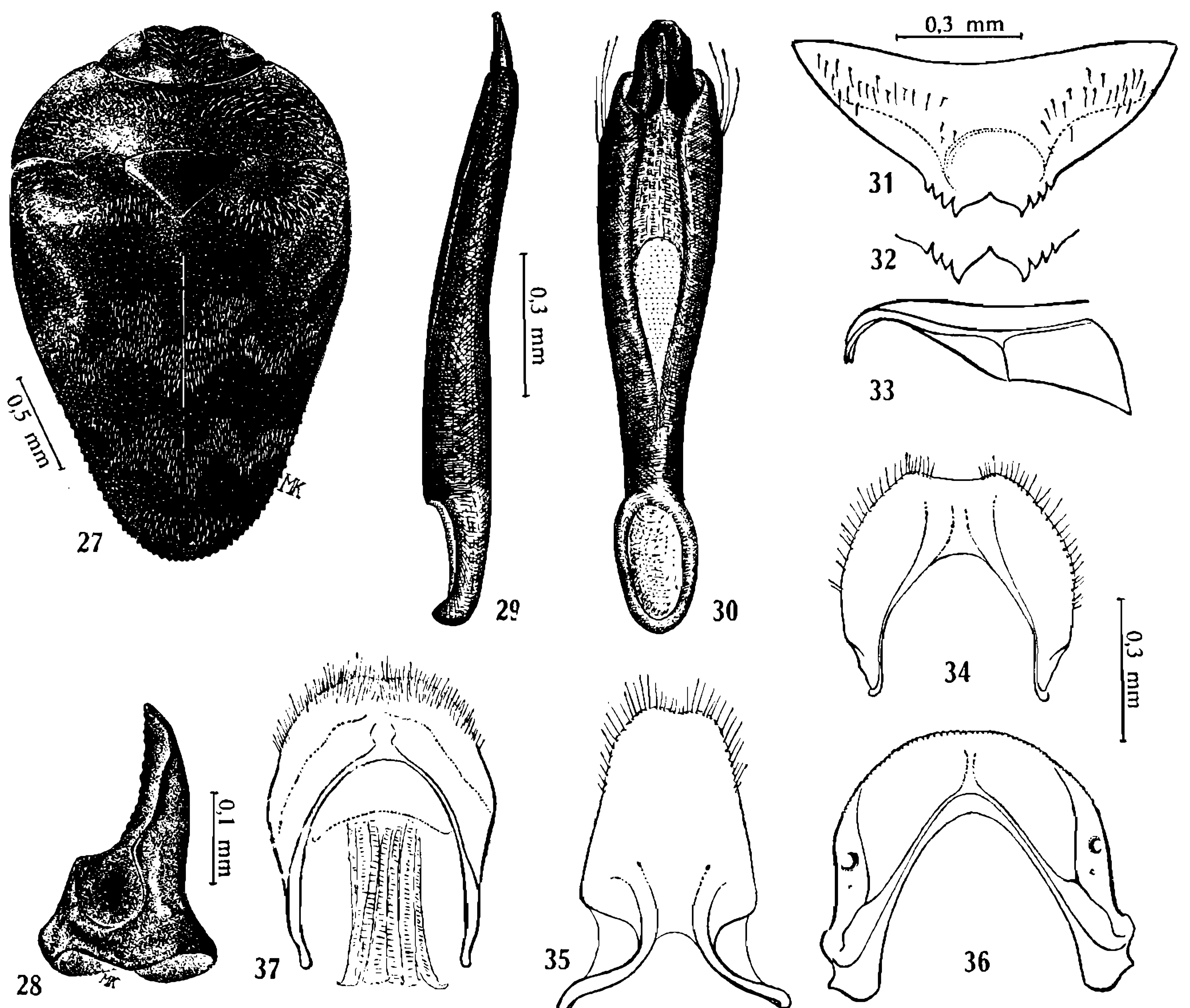

28
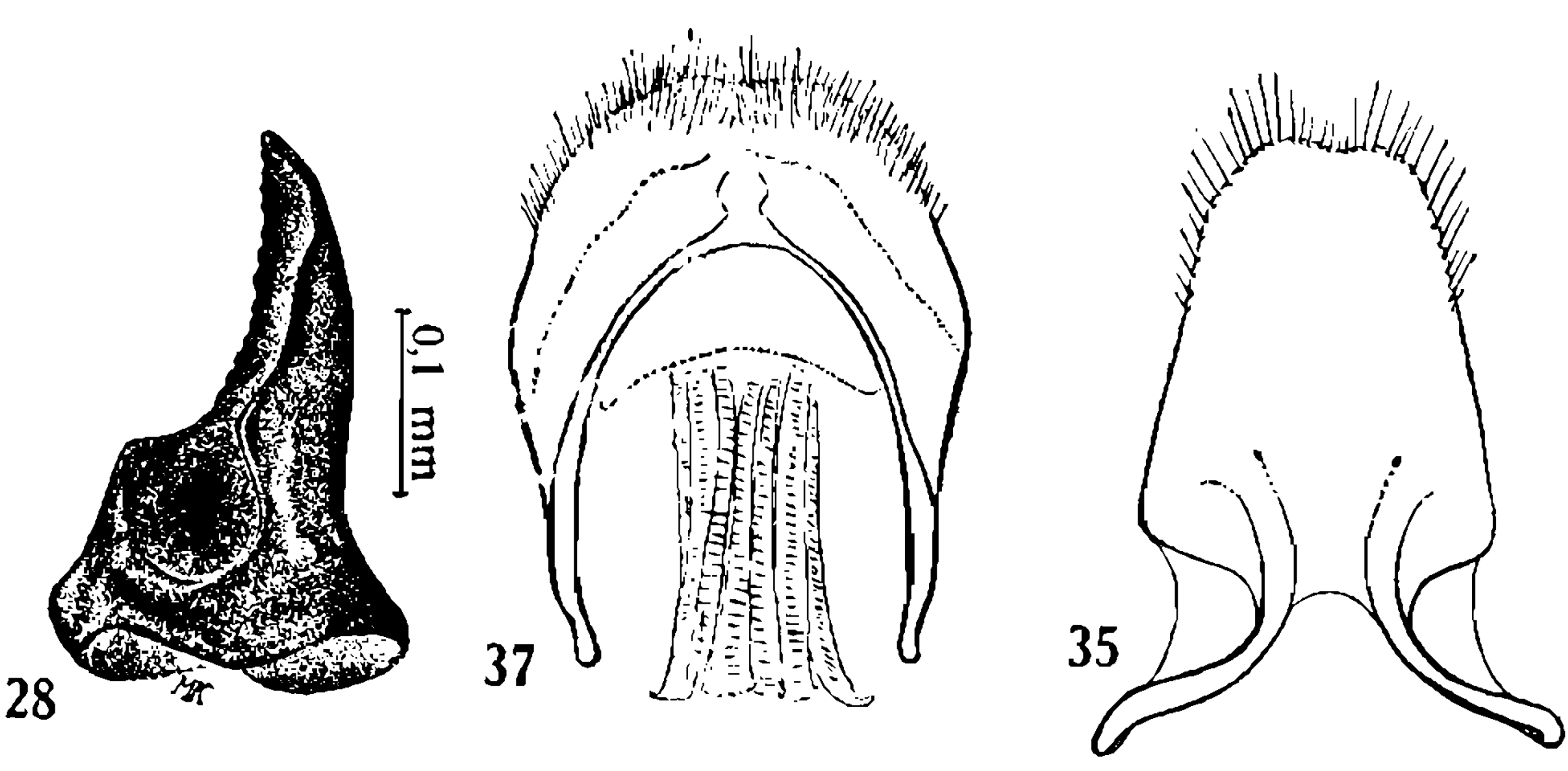

Pachyschelus mimus obenberger, 1925 - Alótipo macho - Fig. 27: Vista dorsal; fig. 28: mandíbula; fig. 29: edeago, vista lateral; fig. 30: edeago, vista dorsal; fêmea - fig. 31: VII-esternito, vista ventral; fig. 32: bordo anal do VII-esternito, vista posterior; fig. 33: VII-esternito, vista lateral; alótipo macho - fig. 34: VIII-esternito; fig. 35: IX-esternito; fig. 36: VIII-tergito; fig. 37: IX+X-tergito. Orig.

Abdômen: Com uma pontuação média e rasa da qual emergem pelinhos poucos conspícuos. Pigídio acuminado. Genitália com o edeago longo e estreito (figs. 29-30), placa basal ovalada e hialina; pêlos apicais em número de 3 de cada lado; ponta do pênis alongada, sub-retangular, com o bordo anterior hemi-hexagonal. Esternito VII (fig. 34) pouco escavado no bordo externo que é guarnecido por uma pilosidade curta e uniforme, interrompida na escavação; esternito IX (fig. 35) com a corpo sub-retangular; tergito VIII (fig. 36) com a margem externa finamente crenulada; tergito IX $+\mathbf{X}$ (fig. 37) com pubescência uniforme no bordo externo.

Patas: Tíbias do $3 .^{\circ}$ par (fig. 39) com a margem externa apresentando um denteado muito fino na metade distal. Com uma forte escavação entre o $1 / 4$ médio-basal e o $1 / 4$ basal, guarnecida por cêrca de 20 cerdas negras e 2 hialinas e mais longas; $1 / 4$ basal com uma esca- 
vação no meio, menos acentuada que a anterior; margem interna com pêlos negros reclinados para o ápice, formando uma meia corôa no ápice, próximo da articulação tarsal. Tarsos curtos, lamelas desenvolvidas.

Alótipo - Macho n. 12.103 na coleção de Coleoptera do Instituto Oswaldo Cruz, margem da estrada BR-5, a 19 quilômetros de Rio Bonito, município de Rio Bonito, Rio de Janeiro, Brasil, 13 de março de 1963, M. Kogan.
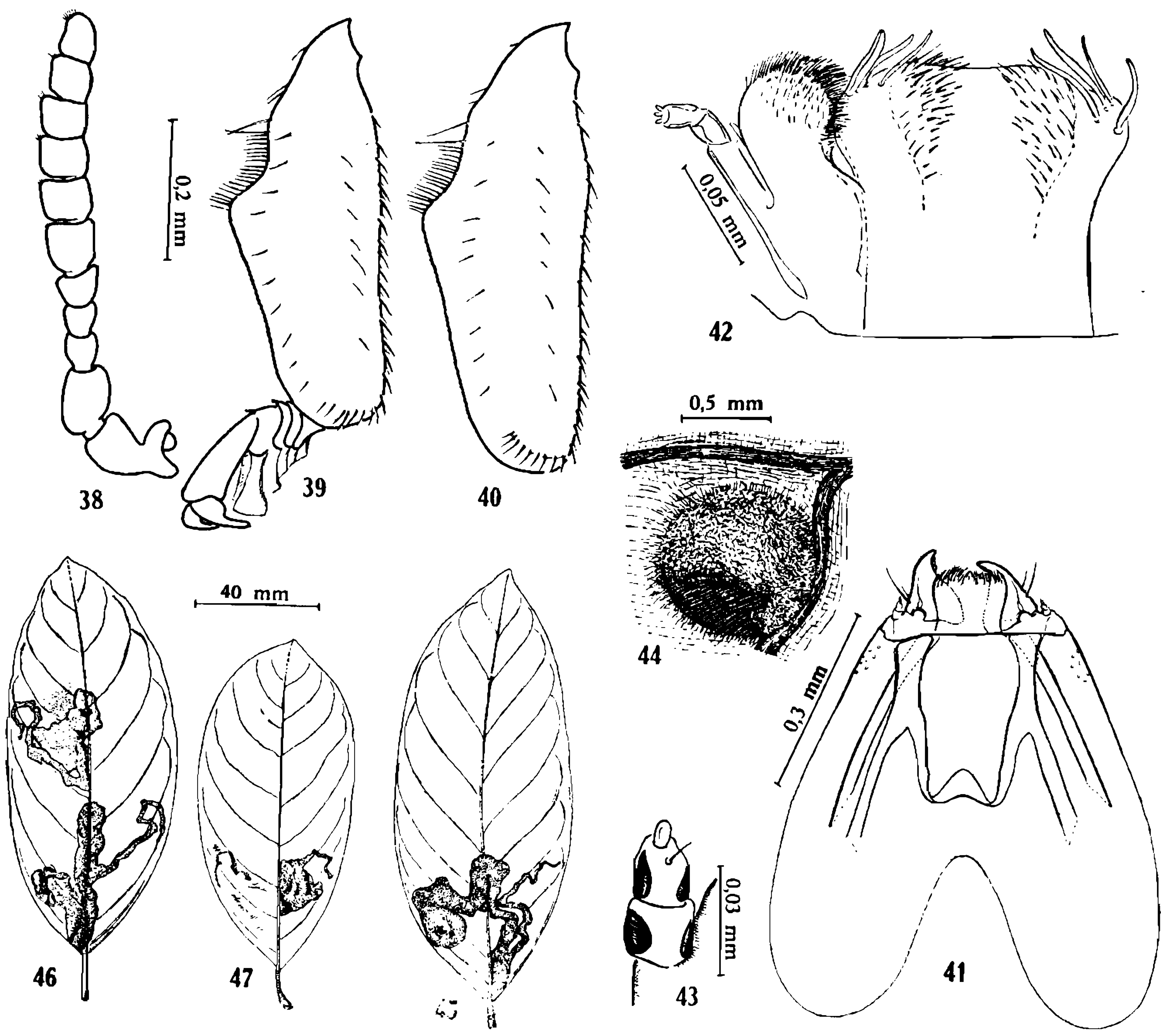

Pachyschelus mimus Obenberger, 1925 - Alótipo macho - Fig. 38: Antena; fig. 39: tíbia+ +tarso posterior esquerdo, vista ventral; fêmea - fig. 40: tíbia +posterior esquerda, vista ventral; larva - fig. 41: cápsula cefálica, vista dorsál; flg. 42: maxila e labro, vista ventral; fig. 43: antena direita; fig. 44: ôvo inserido no tecido follar; figs. 45-47: fôlhas de Psidium araça com minas de Pachyschelus mimus. Obenb. Orig.

F'êmea - Principais proporções de 3 exemplares estudados, inclusive uma $\&$ determinada por OBenberger, procedente de Pernambuco e visivelmente menor que os exemplares coligidos no Rio de Janeiro comprimento: $3,38-3,15-2,76 \mathrm{~mm}$; largura (entre o $1 / 3$ basal e médio dos élitros) : 2,07-1,95-1,68 mm; comprimento do pronoto: 0,51-0,46-0,39 $\mathrm{mm}$; largura do pronoto: 2,02-1,93-1,66 $\mathrm{mm}$; comprimento do escutelo: 
0,32-0,25-0,25 $\mathrm{mm}$; largura do escutelo: 0,69-0,62-0,51 $\mathrm{mm}$; largura da cabeça: 0,99-0,90-0,76 mm; largura entre os olhos: 0,46-0,39-0,35 $\mathrm{mm}$.

A conformação geral, côr e ornamentação elitral são semelhantes às do macho. Bordo posterior do pigídio (figs. 31-33) com 8 dentes divididos em dois grupos de 4, separados por uma forte escavação em "arco-flamejante"; esternito VII com uma depressão circular perto do pigídio e com finos pêlos reclinados, de ambos os lados, próximo da sutura do esternito VI.

Material estudado - 5 ô $\hat{o}$ e 3 o ㅇ, mesma procedência, data e colecionador do alótipo, 1 ô e 1 q na coleção do I. O. C., e $\hat{o}$ e 1 q na coleção do I. P. E. A. C. S., 1 ô e 1 \& na coleção do Autor, 1 ô na coleção Campos Seabra e 1 is na coleção do Dept. de Zool. de S. Paulo; 1 ô Barueri, S. Paulo, 15-X-1963, K. Lenko, n.o 31.470 da coleção do Dept. de Zoologia de S. Paulo; 1 \& - Tigipió, Pernambuco, 25-XI-1914, J. F. Zikán, Obenberger, det., na Coleção do I. O. C.; 1 \& - Barra do Tapirapé, Mato Grosso, de XII-1960, B. Malkin, na coleção do Dept. de Zoologia de S. Paulo.

Discussão $-P$. mimus Obenb. assemelha-se, em suas características externas, à $P$. subundulatus Kerr. espécie com a qual é freqüentemente confundido. A estrutura do pigídio da fêmea, a genitália do macho e a etologia das espécies permite, no entanto, distingui-las com segurança. Ao descrever $P$. mimus, Obenberger referiu-se a esta espécie como rara, devido certamente a baixíssima freqüência com que aparecia nas numerosas coleções que êste autor recebia para estudar. Como acontece tão freqüentemente um melhor conhecimento dos hábitos dos insetos altera radicalmente êste conceito de raridade.

\section{DADOS BIOLÓGICOS}

Ôvo e oviposição (fig. 44) - A oviposição se faz na página inferior da fôlha; o ôvo observado no início da mina é arredondado, com cêrca de $0,82 \mathrm{~mm}$ de diâmetro; muito achatado, com o córion negro brilhante; apresenta-se incluso no tecido epidérmico, recoberto pela película externa da epiderme foliar. As posturas são isoladas, encontrando-se no máximo duas por fôlha, e localizadas na periferia, sempre junto de alguma nervura secundária.

Ao redor do ôvo observam-se, em alguns casos, escaras por vêzes muito superficiais e dispostas irregularmente, por vêzes mais profundas e em disposição radial em relação ao ôvo.

Larva (figs. 41-43) - Foram estudadas apenas as cápsulas cefálicas de diversas larvas, retiradas de exúvias encontradas no interior da mina e cuja descrição damos a seguir.

Cápsula cefálica ovalada, bilobada posteriormente. Labro quadrangular, dilatado lateralmente, nos ângulos anteriores que são guarnecidos por vários pêlos espatulados; mandíbulas afiladas, com a crista ventral saliente e um tufo de longos pêlos, internamente, perto da base, 
além de apresentar um outro pêlo na face dorsal, emergindo de um processo alongado, biglobuloso; maxilas com o lobo apical fortemente pubescente, palpos bi-segmentados apresentando algumas papilas na extremidade. Antenas tri-segmentadas, segmento I sub-cilíndrico, curto, quase tão largo quanto longo, II - mais estreito e tão longo quanto I, com uma forte cerda sub-apical, III - muito curto, estreito e arredondado na ponta. Tentório com o ramo dorsal formando um "M", com os braços internos proeminentes e recurvados fortemente para baixo e para diante; os troncos basais são grossos; os ramos ventrais são simples, reçurvados e grossos na base. Olhos ou manchas ocelares não observados.

Pré-pupa e pupa - Não observados.

Hospedeiro - Psidium araça Raddi, Myrtaceae, (Araçá-do-campo). Esta espécie ocorre em estado nativo desde as Guianas até S. Paulo.

Mina (figs. 45-47) - Muito irregular e atípica devido à confluência das faixas minadas. Geralmente o início é nìtidamente ofioide, sobrevindo após um desenvolvimento irregular e sem forma definida, por vêzes pustular (fig. 47) por vêzes visceriforme (fig. 46). Desenvolve-se no tecido paliçádico (mina de superfície superior).

As dejeções apresentam-se filamentosas, no início ocupam todo o lume da mina, concentrando-se depois em um dos lados e sendo muito esparsas no final.

A câmara pupal não apresenta contôrno regular, é pouco saliente em relação ao resto da lesão; internamente é forrada por uma película esbranquiçada, muito tênue mas resistente, formando uma cápsula arredondada com cêrca de $6 \mathrm{~mm}$ de diâmetro. Nos seus limites externos chega a ter $16 \mathrm{~mm}$ nos locais de maior largura e cêrca de $7 \mathrm{~mm}$ nos mais estreitos. O opérculo de saída é circular, com cêrca de $2,3 \mathrm{~mm}$ de diâmetro; é central em relação a câmara pupal interna, mas pode parecer excêntrico quando se observa o contôrno externo da mesma.

O comprimento foi sòmente medido nas minas representadas nas figuras: 46 e 45 sendo respectivamente $115 \mathrm{~mm}$ e $165 \mathrm{~mm}$; a largura varia de $1 \mathrm{~mm}$ no início até mais de $7 \mathrm{~mm}$ próximo da câmara pupal.

Normalmente observa-se uma única mina completa por fôlha e, ocasionalmente encontram-se duas (fig. 46).

\section{SUMMARY}

This paper deals with two Brazilian species of the genus Pachyschelus Sol., namely: P. urvilleae sp. n. and P. mimus Obenberger, 1925. $P$. urvilleae $\mathrm{sp}$. $\mathrm{n}$. is described based on specimens reared from leafmined Urvillea glabra Cam. (Sapindaceae); it seems to be related to $P$. vanrooni Obenb., 1923, from which it can be distinguished by the absence of sexual dichroism, structural details of female pygidium and, as supposed, by the male genitalia (still unknown in P. vanrooni) . 
P. mimus Obenberger, 1925, was reared from Psidium araça Raddi (Myrtaceae), and the male allotype is described.

Oviposition, larval cephalic capsules and mines of both species are described, as well as other developmental stages of $P$. urvilleae. Some larvae of the latter were found parasitized by Tetrastichus sp.

\section{REFERÊNCIAS BIBLIOGRÁFICAS}

APT, O., 1954, Neue Trachydinen aus dem Ungarischen Naturwissenschaftlichen Museum (Col., Buprestidae). Ann. hist. nat. Mus. hung. - Eudapest, (N. S.) 5: 231-242.

BLACKWELDER, R. E., 1944, Checklist of the coleopterous insects of Mexico, Central America, the West Indies and South America. U. S. Nat. Mus. Bull., 185 (2) : 185-341.

CoBos, A. 1956, Cuarta nota sobre Buprestídos (Ins., Coleoptera) neotropicales. Sobre la posición sistemática del género Trigonogenium Gem. et Harold y diversas descripciones de especies nuevas. Arch. Inst. Aclimatacion, Almeria, 5: 69-95, 39 figs.

Coвos, A., 1958, Tercera nota sobre Buprestidos (Ins., Coleoptera) neo-tropicales descripciones y rectificaciones diversas. Acta Zool. Lilloana, 15: 83-102, 25 figs.

Coвos, A., 1959-a, Octava nota sobre Buprestidos neotropicales. Rectificaciones $\mathrm{y}$ descripciones diversas. (Coleoptera, Buprestidae). Bull. Inst. royal Sci. nat., Belgique, 35 (2) : 2-47, 33 figs.

Cosos, A., 1959-b, Novena nota sobre Buprestidos neotropicales. Rectificaciones y descripciones diversas. (Coleoptera, Buprestidae). Arch. Inst. de Aclimatacion, Almeria, 8: 29-43, 9 figs.

FISHER, W. S., 1925, A revision of the West Indian Coleoptera of the family Buprestidae. Proc. Unit. S. Nat. Mus., 65 (9): 1-207.

Fisher, W. S., 1929, Notes on leaf mining Buprestidae (Coleoptera), with descriptions of new species. Proc. Ent. Soc. Wash., 31: 177-182.

Fisher, W. S., 1931, A new leaf mining buprestid from the Canal Zone (Coleoptera). Proc. Ent. Soc. Wash., 33: 42-43.

Fisher, W. S., 1933, New species of Buprestid beetles from Mexico and Central America. Proc. U. S. Nat. Mus., 82 (27): 1-47.

KogAN, M., 1963, Contribuição ao conhecimento da sistemática e biologia de Buprestídeos minadores' do gênero "Pachyschelus", Solier, 1833. (Coleoptera, Buprestidae). Mem. Inst. Oswaldo Cruz, 61 (3): 429-458, 81 figs.

Obenberger, J., 1923, Eine Serie neuer Buprestidenarten. Tijdisch. voor Ent. (Hague) , 66: 1-32, 2 figs.

OBENBERGER, J., 1925, Révision monographique des Trachydes pachysceloides de l'Amerique (Coleop., Buprest.) - (Titulo Tb. em tcheco). Sborn. Ent. Odd. Nar. Mus. Praze, 3: 3-149, 111 figs.

OBENBERGER, J., 1932, De generis Pachyschelus Sol. Americae meridionales speciebus novis. Cas. Ceskoslovenke Spol. Ent., 29: 14-22.

OBENBERGER, J., 1937, Buprestidae, em W. Junk, Coleopterorum Catalogus, 13 $(152,157): 935-1714$.

Obenberger, J., 1939, Uber die von Herrn H. Schmidt in Costa Rica gesammelten Buprestiden (Coleoptera). Arb. Morph. Tax Ent. Berlin-Dahlen, 6 (4) : 301-314.

OBENBERGER, J., 1940, De generis Pachyschelus Solier regionis neotropicae speciebus novis. (Col., Bupr.). (Título tb. em Tcheco). Sbor. Ent. Odd. Narsd. Mus. Praze, 18: 172-176. 
Obenberger, J., 1960, Ein neuer Pachyschelus aus Brasilien (Coleoptera, Buprestidae). Deutsche Ent. Zett., 7 (4-5): 442-443.

Solier, A. Z. Z., 1833, Essai sur les buprestides. Ann. Soc. Ent. France, 2: 261-316.

THERY, A., 1936, Pachyschelus du Tonkin (Coleopt., Buprestidae) Livre jubilaire de M. Eugene - Louis Bouvier,: 343-347, 4 figs.; Institut National Agronomique. Firmin - Didot et Cie, Imp.

Vogt, G. B., 1949, Five new Buprestidae from South Texas (Coleoptera) Ann. Ent. Soc. Amer., Columbus, 42: 48-54, 10 figs. 